\title{
Pemanfaatan media pembelajaran berbasis augmented reality menggunakan aplikasi Ar_Jarkom pada mata kuliah instalasi jaringan komputer
}

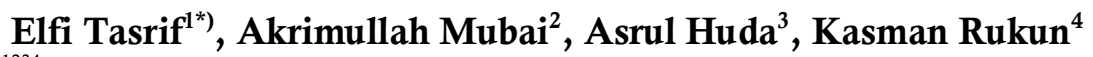 \\ ${ }^{1234}$ Universitas Negeri Padang, Indonesia
}

\section{Article Info \\ Article history: \\ Received Oct 17th, 2020 \\ Revised Nov 28th, 2020 \\ Accepted Des 16th, 2020 \\ Keyword: \\ Augmented reality \\ Ar_jarkom application \\ Computer network \\ Installation courses \\ Learning media}

\begin{abstract}
This study aims to analyzed of the level of practicality, effectiveness, and influence of the application of learning media based on Augmented Reality (AR) in the Computer Network Installation course using a mobile application called AR_JARKOM_INFORMATIKA_UNP. This study used the Research and Development $(\mathrm{R} \& \mathrm{D})$ method with research subjects, namely students in class $2 \mathrm{~F} 3$ and 2F4 of the Informatics Engineering Education Department of Electronics Engineering, Faculty of Engineering, Padang State University who attended the Computer Network Installation lectures for the January-June 2020 semester. The results of this study indicate that AR-based learning media has a practicality level of $88.40 \%$ with a very practical category, then in the effective category based on the post-test score of the experimental class (2F3) which is 73.16 which is higher than the control class (2F4) which is 69.25 and provides $33.6 \%$ contribution to the learning outcomes of Computer Network Installation based on the $r$ square value of 0.336 . So it can be concluded that AR-based learning media has a good level of practicality, effectiveness and influence to be used in the learning process of Computer Network Installation.
\end{abstract}

Corresponding Author:

Elfi Tasrif,

Universitas Negeri Padang

Email: elfitasrif17@gmail.com

\section{Pendahuluan}

Setiap yang bergerak pasti berubah, sama halnya dengan kondisi saat ini dengan revolusi diberbagai bidang. Dibidang sosial telah masuk ke revolusi society 5.0 sedangkan dibidang teknologi telah masuk revolusi industry 4.0, (Chonsawat \& Sopadang, 2021; Skobelev \& Borovik, 2017). Semua ini telah memberikan warna disetiap lini kehidupan, tentunya bagi yang mampu memanfaatkan perubahan ini, maka akan mendapatkan keuntungan. Untuk itu dengan adanya dampak revolusi ini, maka memunculkan suatu tantangan untuk semua negara di dunia, (Neumann, Winkelhaus, Grosse, \& Glock, 2021; Puspita, Fitriani, Astuti, \& Novianti, 2020).

Dalam hal ini perlu ada persiapan dalam menjawab semua tantangan yang ditimbulkan oleh revolusi society dan industry (Amjad, Rafique, \& Khan, 2021). Persiapan ini dapat dilaksanakan dengan mendorong perubahan yang intens diberbagai sektor kehidupan, terutama disektor pendidikan, (Kiryakova, Angelova, \& Yordanova, 2018; Shahroom \& Hussin, 2018).Hal ini disebabkan sektor pendidikan akan menghasilkan manusia yang kompeten, yang dengan kompetensi tersebut seluruh sumber daya akan dapat dimanfaatkan dengan maksimal, sehingga revolusi ini memberikan dampak yang menguntungkan, (Kipper, et al., 2021; Ramdani, Amrullah, \& Tae, 2019). 
Sektor pendidikan dapat direalisasikan dalam bentuk suatu proses pembelajaran. Pembelajaran merupakan proses interaksi peserta didik dengan pendidik dan sumber belajar pada suatu lingkungan belajar (Nasional, 2003). Sumber belajar dapat berbentuk media pembelajaran. Suatu media dapat dikatan media pembelajaran apabila mampu mentransmisikan informasi pembelajaran dari sumber informasi kepada penerima informasi pembelajaran tersebut (Baird \& Fisher, 2005).

Media pembelajaran yang efektif akan menentukan tersampaikannnya informasi pembelajaran dengan baik atau tidak kepada peserta didik yang nantinya akan mempengaruhi capaian belajar peserta didik, (Ramli, 2015). Pengetahuan siswa akan semakin abstrak jika pembelajaran menggunakan media dengan bahasa verbal, sehingga nantinya akan menimbulkan perbedaaan persepsi antara peserta didik dengan pendidik. Pengetahuan akan semakin konkrit jika pembelajaran menggunakan media yang memberikan pengalaman langsung dalam pembelajaran, karena melibatkan semua indra manusia, Edgar Dale dalam (Arsyad, 2019; Lacka, Wong, \& Haddoud, 2021).

Media pembelajaran yang efektif juga akan mampu mendorong peserta didik untuk berlajar secara mandiri, sehingga mampu membentuk pembelajaran berpusat pada siswa (student center) (Halimovna, Nurilloevna, Radzhabovna, Shavkatovna, \& Hamidovna, 2021).Untuk itu dalam mewujudkan media pembelajaran yang efektif perlu pemanfaatan suatu teknologi. Salah satu teknologi tersebut yaitu teknologi virtual yang menjadi salah satu produk dari revolusi industri 4.0 (Ma \& Liu, 2016; Verbruggen, Depaepe, \& Torbeyns, 2021). Hal ini dipilih karena teknologi virtual mampu secara akurat dalam mewakilkan benda nyata dalam menyediakan informasi. Yang mana salah satu contoh dari teknologi virtual itu yakni Augmented Reality (AR) (Hammer, Scheiter, \& Stürmer, 2021).

Augmented Reality (AR) merupakan suatu konsep yang menggabungkan informasi digital(gambar, video, audio, teks) ke dalam lingkungan maya dan ditampilkan secara waktu nyata (Fernández- García, 2021). Teknologi augmented reality menggunakan objek sebagai marker untuk menampilkan gambar, video, audio, teks, dan visual 3D, sehingga teknologi ini mampu menampilkan alat dan bahan praktikum secara virtual 3D bahkan video simulasi dalam pembelajaran (Mubai, Rukun, Tasrif, \& Huda, 2020). Marker yang diperlukan teknologi augmented reality dapat berupa kartu atau kertas, jadi dapat ditanamkan kedalam job sheet yang sudah ada, (Fraga-Lamas, Fernández-Caramés, Blanco-Novoa, \& Vilar-Montesinos, 2018). Kemampuan inilah yang nanti akan memberikan peranan yang besar pada media pembelajaran.

Banyak media pembelajaran yang telah dikembangkan dengan teknologi AR, salah satunya media tersebut yakni media AR_JARKOM_INFORMATIKA-UNP. Media ini dikembangkan oleh (Mubai, et al., 2020) yang merupakan media pembelajaran untuk mata kuliah praktikum Instalasi Jaringan Komputer. Media ini yang terdiri dari buku job sheet dan aplikasinya yang dapat diperoleh secara gratis di Google Play Store. Adapun bentuk dari job sheet dari media ini sebagai gambar berikut.

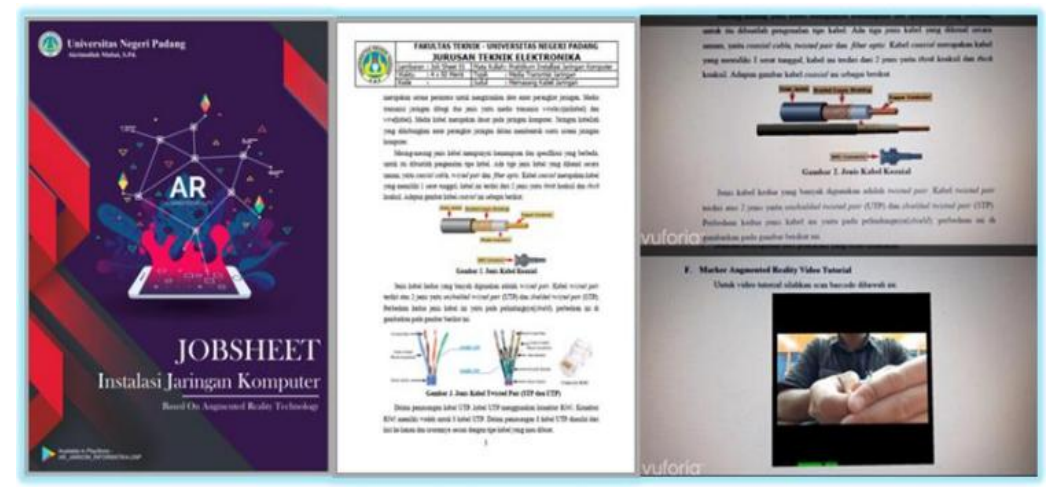

Gambar 1. Job Sheet Media AR_JARKOM_INFORMATIKA-UNP, (Mubai, Rukun, \& Huda, 2020)

Job sheet ini dapat digunakan berbentuk hardcopy atau softcopy dalam fungsinya sebagai marker. Marker dalam job sheet ini berbentuk gambar alat atau bahan praktikum dan juga barcode disetiap akhir dari chapter job sheet. Maker ini nantinya akan di scan oleh aplikasi media pembelajaran ini, yang mana jika dalam proses scan marker ditemukan, maka aplikasi akan menampilkan teks, audio, 3D objek, bahkan video tutorial praktikum dari setiap chapter dalam job sheet. Adapun bentuk dari aplikasi AR dari media ini sebagai berikut. 


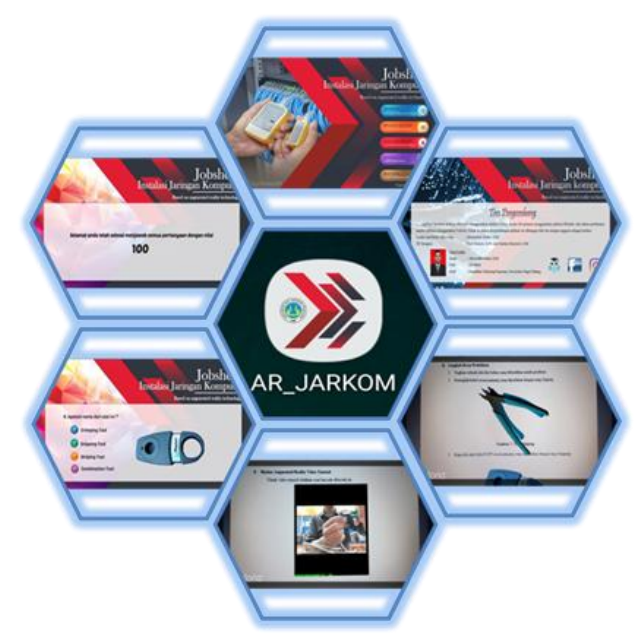

Gambar 2. Aplikasi Media AR_JARKOM_INFORMATIKA-UNP, (Mubai, Rukun, \& Huda, 2020).

Aplikasi media AR_JARKOM_INFORMATIKA-UNP menggunakan perangkat smartphone sehingga mobilitas media ini sangat baik. Kemudian aplikasi media pembelajaran ini juga menggunakan basis sistem Android sehingga interaktifitas media sangat baik. Dan aplikasi media pembelajaran ini juga mampu menghadirkan bahan dan alat bahkan video tutorial praktikum sehingga media ini memungkin untuk digunakan dalam pembelajran mandiri yang mengidentifikasikan media pembelajaran ini memiliki indpendenitas yang baik (Mubai, et al., 2020).

Media pembelajaran AR_JARKOM_INFORMATIKA-UNP telah melewati uji validitas oleh para ahli. Dari hasil uji coba diperoleh tingkat validitas desain yaitu 0,875 dalam kategori valid dan validitas materi yaitu 0,827 dalam kategori valid, yang mengindikasikan bahwa media pembelajaran ini sudah tepat untuk digunakan pada pembelajaran praktikum Instalasi Jaringan Komputer (Mubai, et al., 2020). Untuk itu pada penelitian ini akan dilakasanakan penelitian lanjutan untuk menganalisis tingkat praktikalitas, efektifitas, pengaruh dan persentasi besar pengaruh penerapan media pembelajaran AR_JARKOM_INFORMATIKAUNP terhadap hasil belajar mahasiswa pada praktikum Instalasi Jaringan Komputer.

\section{Metode}

Penelitian ini menggunakan metode Research and Development (R\&D) (Haryati, 2012). Desain metode penelitian menjelaskan penelitian ini memiliki tiga tahapan utama yakni persiapan penelitian, penelitian dan kesimpulan penelitian. Tujuan dari uji penelitian ini untuk menentukan tingkat praktikalitas, efektivitas, pengaruh penerapan media terhadap hasil belajar, dan besar persentasi pengaruh penerapan media pembelajaran berbasis augmented reality menggunanan media AR_JARKOM_INFORMATIKA-UNP pada mata kuliah Instalasi Jaringan Komputer.Rancangan uji menggunakan metode intact-group comparison yang merupakan bagian dari metode pre experimental design (nondesign).Subjek uji coba pada penelitian ini akan dilaksanakan kepada mahasiswa program studi Pendidikan Teknik Informatika dan Komputer kelas 2F3 (kelas eksperimen) dan 2F4 (kelas kontrol) pada semester Januari-Juni 2020 yang mengikuti mata kuliah Instalasi Jaringan dan Komputer.Instrumen yang digunakan dalam mengukur praktikalitas media menggunakan instrumen non test berupa angket. Kemudian untuk mengukur tingkat efektivitas media pembelajaran AR_JARKOM_INFORMATIKA-UNP digunaan instrumen efektivitas yang diambil dari hasil belajar kognitif dan psikomotor mahasiswa melalui soal tes ujian.Nilai teori digunakan untuk mengukur kognitif mashasiswa sehingga instrumen yang digunakan yaitu instument test berupa soal tes uraian. Soal tes uraian yang digunakan terlabih dahulu harus melawati uji validitas, reliabilitas, daya beda, dan indeks kesukaran soal, setelah itu barulah digunakan untuk mengukur kognitif mahasiswa dalam proses ujian. Kemudian dari nilai praktik diperoleh dari penilaian psikomotor mahasiswa. Penilaian psikomotor mahasiswa menggunakan instrumen test berupa rubrik tes kinerja (performance test).Selanjutnya data dianalisi dengan melakukan pengujian berupa uji praktikalitas, uji efektifitas, uji t-tes serta uji r square. 


\section{Hasil dan Pembahasan}

Setelah dilaksanakan penerapan media pembelajaran AR_JARKOM dan kalkulasi pada data hasil penelitian, maka sampailah pada pembahasan dari hasil penelitian. Dimana penelitian penerapan media pembelajaran AR JARKOM telah dilakasanakan dengan tujuan, rancangan dan subjek penelitian yang tepat dan terukur. Hasil penelitian yang pertama yaitu tingkat praktikalitas penerapan media pembelajaran AR_JARKOM pada proses pembelajaran Instalasi Jaringan Komputer yang mengahasilkan data penelitian sebagai berikut.

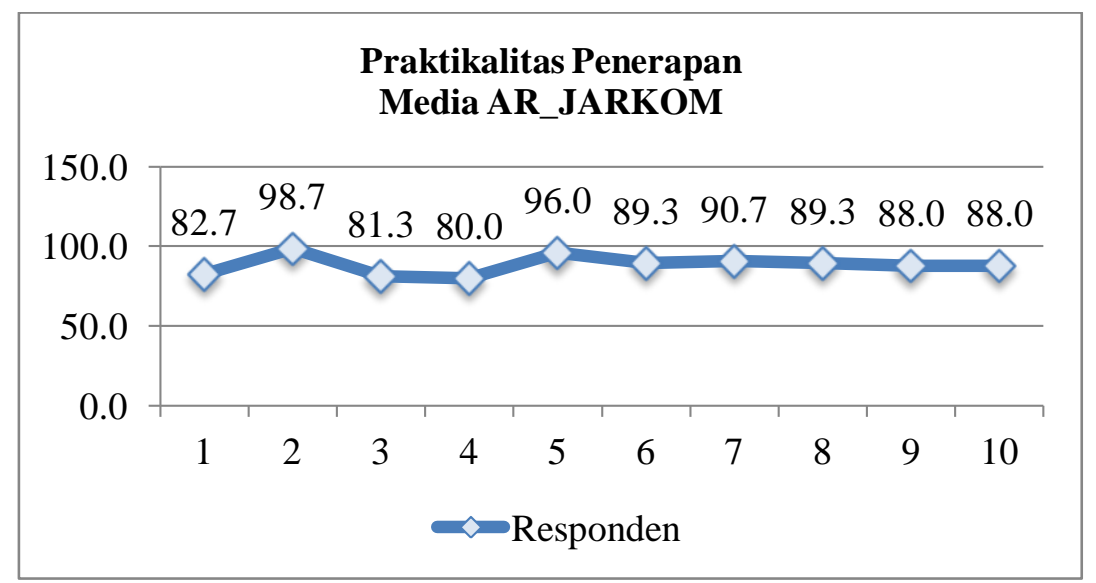

Gambar 3. Data Hasil Praktikalitas Media AR_JARKOM

Penelitian praktikalitas dilakasanakan terhadapa 10 mahasiswa kelas $2 \mathrm{~F} 3$ sebagai kelas eksperimen. Hasil dari penelitian praktikalitas penerapan media pembelajaran AR_JARKOM meperoleh rata-rata nilai $88.4 \%$ dengan kategori "Sangat Praktis".Selanjutnya pada pengukuran efektifitas media pembelajaran berbasis Augmented Reality (AR) menggunakan aplikasi AR_JARKOM dilaksanakan dengan membandingkan hasil post-test kelas $2 \mathrm{~F} 3$ dengan kelas $2 \mathrm{~F} 4$ yang menggunakan media pembelajaran berbasis cetak. Data post-test diperoleh dari hasil Ujian Tengah Semester (UTS) dengan data sebagai berikut.

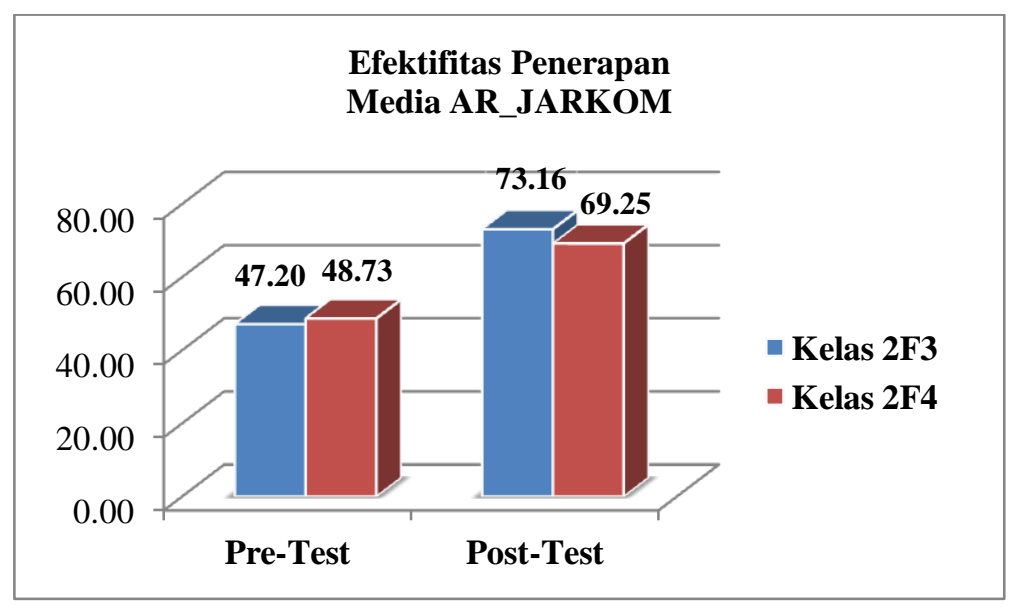

Gambar 4. Data Hasil Efektifitas Media AR_JARKOM

Pemilihan kelas 2F3 dan 2F4 dalam uji efektifitas media pembelajaran dikarenakan kedua kelas ini memiliki selisih nilai pre-test yang rendah yakni 47.2 dan 48.73 . Setelah dilaksanakan penelitian maka diperoleh bahwa media pembelajaran Instalasi Jaringan Komputer berbasis AR lebih efektif dibandingkan media job sheet yang ada konvensional (berbasis cetak) berdasarkan nilai post-test dari kelas ekperimen dengan nilai 73,16 lebih tinggi dari kelas kontrol dengan nilai 69,25. Sedangkan besar pengaruh dari penerpan media pembelajaran Instalasi Jaringan Komputer berbasis AR dikur dengan menggunakan uji $\mathrm{R}$ Square yang hasilnya sebagai berikut ini. 


\begin{tabular}{|l|c|c|c|c|}
\hline \multicolumn{4}{|c|}{ Model Summary } \\
\hline Model & $\mathrm{R}$ & $\mathrm{R}$ Square & $\begin{array}{c}\text { Adjusted R } \\
\text { Square }\end{array}$ & $\begin{array}{c}\text { Std. Error of the } \\
\text { Estimate }\end{array}$ \\
\hline 1 & $.580^{\mathrm{a}}$ & 0.336 & 0.253 & 10.07313 \\
\hline \multicolumn{2}{|l|}{ a. Predictors: (Constant), Media Pembelajara } \\
\hline
\end{tabular}

Gambar 5. Data Hasil Uji R Square

Uji R Square dihitung menggunakan tools SPSS dengan nilai R Square yang diperoleh yaitu 0,336 . Nilai 0,336 selanjutnya dikalikan dengan $100 \%$ sehingga menghasilkan 33,6\%. Nilai 33,6\% memberikan informasi bahwa hasil belajar Instakasi Jaringan Komputer dipengaruhi media pembelajaran berbasis Augmented Reality (AR) sebesar 33,6\%, sedangkan 66,4\% lagi dipengaruhi faktor lain.

Dalam menjawab tantangan perubahan yang disebabkan revolusi society dan industry terhadap dunia pendidikan, maka pemanfaatan teknologi dalam pembelajaran sudah hal yang harus dilakukan (Wahyono, 2019). Penggunaan teknologi terkini seperti teknologi Augmented Reality (AR) dapat menjawab kebutuhan akan perubahan-perubahan yang terjadi saat ini (Kiryakova, et al., 2018). Teknologi Augmented Realty (AR) mampu memberikan gambaran visual objek 3D dan video dalam setiap smartphone pengguna dengan marker berbasis softcopy atau hardcopy, (Mubai, Rukun, \& Huda, 2020). Hal ini membuat teknologi AR menjadi pilihan yang efektif untuk dijadikan basis pembelajaran terutama pada media pembelajaran, (Kiryakova, et al., 2018; Mustami, Syamsudduha, Safei, \& Ismail, 2019).

Seperti penerapan teknologi AR pada penelitian ini yang ditanamkan pada media pembelajaran Instalasi Jaringan Komputer berupa job sheet. Temuan dari penggunaan media pembelajaran Instalasi Jaringan Komputer AR memiliki tingkat praktikalitas dalam kategori sangat praktis. Hal ini juga ditemukan oleh beberapa beberapa penelitian yang menemukan bahwa penggunakan media pembelajaran berbasis teknologi AR memiliki tingkat praktikalitas yang baik (praktis) (Hamzah \& Kurniadi, 2019; Murfi \& Rukun, 2020). Sehingga dengan penerapan media pembelajaran berbasis AR sangat membantu mahasiswa dalam proses pembalajaran Instalasi Jaringan Komputer secara mandiri dengan media pembelajaran berbasis AR yang mobile, interaktif dan independen, (Karakus, Ersozlu, \& Clark, 2019; Mubai, et al., 2020).

Penerapan media pembelajaran berbasis AR pada mata kuliah Instalasi Jaringan Komputer juga memberikan dampak yang baik pada hasil belajar siswa. Seperti hasil memperoleh data hasil penelitian bahwa media pembelajaran berbasis AR merupakan pembelajaran yang efektif dalam pembebelajaran (Murfi \& Rukun, 2020; Mustami, et al., 2019). Hal ini juga dibuktikan pada penelitian ini bahwa pemanfaatan media pembelajaran berbasis AR lebih efektif dari pada penggunaan media pembelajaran berbasis cetak pada mata kuliah Instalasi Jaringan Komputer semester Januari-Juni 2020 di Universitas Negeri Padang (Bakri, Sumardani, \& Muliyati, 2019).

Pada implementasinya pengaruh media pembelajaran berbasis Augmented Reality (AR) juga memiliki andil yang cukup besar dalam mempengaruhi hasil belajar peserta didik. Aryani et al.,(2019), dalam penelitian "Penerapan Model Pembelajaran Inkuiri Terbimbing Berbentuk Augmented Reality pada Peserta Didik untuk Meningkatkan Minat dan Pemahaman Konsep IPA Pramita" mendapatkan bahwa sebesar 64\% peningkatan pemahaman konsep IPA memanfaatkan teknologi Augmented Reality pada model pembelajarannya (Aryani, Akhlis, \& Subali, 2019; Sumardani, Saraswati, Putri, Bakri, \& Muliyati, 2020). Hal ini juga diperoleh dari penelitian ini dengan pemanfaatan teknologi AR pada media pembelajaran, yang memberikan kontribusi pengaruh terhadap hasil belajar sebersar 33,6\%.

Beberapa hasil penelitian diatas memperlihatkan bahwa teknologi AR merupakan teknologi yang praktis, efektif dan memberikan pengaruh yang baik dalam proses pembelajaran Instalasi Jaringan Komputer terhusus dalam bentuk media pembelajaran. Sehingga dengan hasil penelitian ini, maka penerapan media pembelajaran berbasis AR mampu memberikan kontribusi yang baik dalam peningkatan hasill belajar Instalasi Jaringan Komputer berupa media pembelajaran yang praktis dan efektif.

\section{Simpulan}

Augmented Reality (AR) mempunyai karakteristik yang sesuai dengan era revolusi saat ini, dimana teknologi aplikasi AR ini berbasis teknologi yang mampu menghadirkan media yang mobile, interaktif dan independen, sehingga teknologi AR merupakan salah satu solusi media pembelajaran yang relevan dengan perkembangan pembelajaran pada era revolusi society 5.0 dan revolusi industry 4.0. Berdasarkan hasil dari 
pengimpelementasian media pembelajaran berbasis Augmented Reality (AR) menggunakan aplikasi AR_JARKOM_INFORMATIKA-UNP diperoleh bahwa media pembelajaran berbasis AR memiliki tingkat praktikalitas $88,4 \%$ dengan kategori sangat praktis, kemudian dalam kategori efektif berdasarkan nilai posttest dari kelas ekperimen(2F3) yaitu 73,16 yang lebih tinggi dari kelas control (2F4) yakni 69,25 dan memberikan kontribusi 33,6\% terhadap hasil belajar Instalasi Jaringan Komputer berdasarkan nilai r square 0,336. Sehingga implikasi pemanfaatan media pembelajaran berbasis AR dapat memberikan dampak yang baik terhadap proses pembelajaran berupa media pembelajaran yang praktis dan efektif.

\section{Referensi}

Amjad, M. S., Rafique, M. Z., \& Khan, M. A. (2021). Leveraging Optimized and Cleaner Production through Industry 4.0. [Article]. Sustainable Production and Consumption, 26, 859-871.

Arsyad, A. (2019). Media pembelajaran edisi revisi. Jakarta: Rajawali Pers.

Aryani, P. R., Akhlis, I., \& Subali, B. (2019). Penerapan Model Pembelajaran Inkuiri Terbimbing Berbentuk Augmented Reality pada Peserta Didik untuk Meningkatkan Minat dan Pemahaman Konsep IPA. UPEJ Unnes Physics Education Journal, 8(2), 90-101.

Baird, D. E., \& Fisher, M. (2005). Neomillennial user experience design strategies: Utilizing social networking media to support "always on" learning styles. Journal of educational technology systems, 34(1), 5-32.

Bakri, F., Sumardani, D., \& Muliyati, D. (2019). The augmented reality application for simulating electromotive force concept. Paper presented at the Journal of Physics: Conference Series.

Chonsawat, N., \& Sopadang, A. (2021). Smart SMEs 4.0 maturity model to evaluate the readiness of SMEs implementing industry 4.0. CMUJ. Nat. Sci, 20(2), e2021027.

Fernández- García, C. (2021). Effect of augmented reality on school journalism: A tool for developing communication competencies in virtual environments. The Electronic Journal of Information Systems in Developing Countries, e12169.

Fraga-Lamas, P., Fernández-Caramés, T. M., Blanco-Novoa, Ó., \& Vilar-Montesinos, M. A. (2018). A review on industrial augmented reality systems for the industry 4.0 shipyard. Ieee Access, 6, 1335813375.

Halimovna, K. S., Nurilloevna, M. O., Radzhabovna, K. D., Shavkatovna, R. G., \& Hamidovna, R. I. (2021). The Role of Modern Pedagogical Technologies in the Formation of Students' Communicative Competence. Religación, 4, 261-265.

Hammer, M., Scheiter, K., \& Stürmer, K. (2021). New technology, new role of parents: How parents' beliefs and behavior affect students' digital media self-efficacy. [Article]. Computers in Human Behavior, 116.

Hamzah, S., \& Kurniadi, D. (2019). Pengembangan Media Pembelajaran Perangkat Keras Jaringan Berbasis Augmented Reality Pada Platform Android. VoteTEKNIKA: Jurnal Vocational Teknik Elektronika dan Informatika, 7(3), 146-157.

Haryati, S. (2012). Research and Development (R\&D) sebagai salah satu model penelitian dalam bidang pendidikan. Majalah Ilmiah Dinamika, 37(1), 15.

Karakus, M., Ersozlu, A., \& Clark, A. C. (2019). Augmented reality research in education: a bibliometric study. EURASIA Journal of Mathematics, Science and Technology Education, 15(10), em1755.

Kipper, L. M., Iepsen, S., Dal Forno, A. J., Frozza, R., Furstenau, L., Agnes, J., et al. (2021). Scientific mapping to identify competencies required by industry 4.0. [Article]. Technology in Society, 64.

Kiryakova, G., Angelova, N., \& Yordanova, L. (2018). The potential of augmented reality to transform education into smart education. TEM Journal, 7(3), 556.

Lacka, E., Wong, T. C., \& Haddoud, M. Y. (2021). Can digital technologies improve students' efficiency? Exploring the role of Virtual Learning Environment and Social Media use in Higher Education. [Article]. Computers and Education, 163.

Ma, X., \& Liu, H. (2016). The reformation and restruction of traditional manufacturing industry study in industry 4.0 times. International Journal of Science, $3((7))$, 88-93.

Mubai, A., Rukun, K., Tasrif, E., \& Huda, A. (2020). Augmented Reality (AR)-Based Learning Media on the Subject of Computer Network Installation. Jurnal Pendidikan dan Pengajaran, 53(2), 213-226.

Murfi, M. S., \& Rukun, K. (2020). Pengembangan Rancangan Media Pembelajaran Augmented Reality Perangkat Jaringan Komputer. INVOTEK: Jurnal Inovasi Vokasional dan Teknologi, 20(1), 69-76.

Mustami, M. K., Syamsudduha, S., Safei, \& Ismail, M. I. (2019). Validity, practicality, and effectiveness development of biology textbooks integrated with augmented reality on high school students. International Journal of Technology Enhanced Learning, 11(2), 187-200. 
Nasional, D. P. (2003). Undang-Undang Nomor 20 Tahun 2003 Tentang Sistem Pendidikan Nasional. Jakarta: Depdiknas, 33.

Neumann, W. P., Winkelhaus, S., Grosse, E. H., \& Glock, C. H. (2021). Industry 4.0 and the human factor - A systems framework and analysis methodology for successful development. [Article]. International Journal of Production Economics, 233.

Puspita, Y., Fitriani, Y., Astuti, S., \& Novianti, S. (2020). Selamat Tinggal Revolusi Industri 4.0, Selamat Datang Revolusi Industri 5.0. Paper presented at the Prosiding Seminar Nasional Program Pascasarjana Universitas PGRI Palembang.

Ramdani, Z., Amrullah, S., \& Tae, L. F. (2019). Pentingnya kolaborasi dalam menciptakan sistem pendidikan yang berkualitas. MEDIAPSI, 5(1), 40-48.

Shahroom, A. A., \& Hussin, N. (2018). Industrial revolution 4.0 and education. International Journal of Academic Research in Business and Social Sciences, 8(9), 314-319.

Skobelev, P., \& Borovik, S. Y. (2017). On the way from Industry 4.0 to Industry 5.0: From digital manufacturing to digital society. Industry 4.0, 2(6), 307-311.

Sumardani, D., Saraswati, R. R., Putri, A., Bakri, F., \& Muliyati, D. (2020). System Implementation of Augmented Reality Application in Student Worksheet. Jurnal Informatika, 8(1), 10-18.

Verbruggen, S., Depaepe, F., \& Torbeyns, J. (2021). Effectiveness of educational technology in early mathematics education: A systematic literature review. [Review]. International Journal of ChildComputer Interaction, 27.

Wahyono, H. (2019). Pemanfaatan Teknologi Informasi dalam Penilaian Hasil Belajar pada Generasi Milenial di Era Revolusi Industri 4.0. Proceeding of Biology Education, 3(1), 192-201. 